\title{
FIREARM INJURIES IN NSW
}

D ebate on the relationship between gun ownership and preventable serious injury re-emerged after the shotgun deaths of seven people at Strathfield Plaza in Sydney in August and other firearm-related incidents in the following weeks. In view of these developments we reviewed the available mortality and hospital statistics collections to prepare a profile of firearm injuries in NSW. This report focuses on the numbers and trends in serious injury caused by firearms since 1969 and examines the role of firearms in suicide and homicide.

We extracted information on firearm-related deaths and hospital admissions from the NSW mortality data for the years 1969 to 1988 and the Inpatient Statistics Collection for the calendar years 1983, 1986 and the financial year 1988-9. We obtained mortality data from the Registrar of Births, Deaths and Marriages and reported them according to year of death between 1969 and 1987, and year of registration for 1988. A list of external cause codes used to identify firearm injury cases is contained in Table 1.

\section{SERIOUS INJURY}

In NSW each year an estimated 450 people are injured by firearms and either die or are admitted to hospital. In most cases the injuries are intentional, either being self-inflicted or the result of interpersonal violence. A smaller, but significant, number of cases is unintentional in nature. Importantly, nearly half serious firearm injury incidents result in death.

\section{Deaths}

In NSW for the five years between 1984-88 there were 1041 deaths caused by firearms, giving an annual figure of about 210 deaths. Firearms ( 8 per cent) ranked third as a cause of injury-related death after motor vehicle crashes ( 35 per cent) and falls (12 per cent), and caused more deaths than poisoning (4 per cent), drowning ( 4 per cent), fire (2 per cent) and bicycle accidents (1 per cent) (Figure 1).

These data indicate that males are 6.5 times more likely to die from a gunshot wound than females and that young people are at greatest risk from firearms with a death rate in the 15-24 age group of $5.7 / 100,000$ /year (Figure 2).

The fatality rate in urban residents was $2.7 / 100,000 /$ year between $1984-88$, while the rate for rural inhabitants was 6.1/100,000/year, making rural residents 2.3 times more likely to die from this cause.

Three-quarters of firearm deaths were attributed to suicide, 20 per cent to interpersonal violence and 5 per cent to other causes such as police intervention, unintentional firearm deaths or undetermined in nature.

The number of firearm-related deaths has remained relatively stable since 1970 . This means the crude mortality rate declined by less than 1 per cent a year from a three-year running average of $4.2 / 100,000$ in 1970 to $3.7 / 100,000$ in 1987 (Figure 3).

\begin{tabular}{|lrr|}
\hline \multicolumn{2}{|l|}{ TABLE 1 } & \\
\hline $\begin{array}{l}\text { EXTERNAL CAUSE CODES USED TO } \\
\text { IDENTIFY FIREARM INJURIES }\end{array}$ & \\
\hline Type of Firearm Injury & ICD-9 & ICD-8 \\
\hline Homicide & $9650-9654$ & $9650-9659$ \\
Suicide & $9550-9554$ & $9550-9559$ \\
Unintentional & $9220-9229$ & $9220-9229$ \\
Undetermined purpose & $9850-9854$ & $9850-9859$ \\
Legal intervention & $9700-9709$ & $9700-9709$ \\
\hline
\end{tabular}

\section{Hospitalisations}

In NSW during the 1988-9 financial year, 244 hospital separations were due to firearm injuries. These cases accounted for less than 1 per cent of the total hospital admissions for injury that year and they occupied 2158 hospital bed days (with stays ranging from one day to more than three months). Males with gunshot wounds outnumbered females five to one.

In contrast to firearm deaths, only a small proportion of the hospital cases had injuries that were caused intentionally; 15 per cent of all cases with firearm injury were self-inflicted and 11 per cent due to interpersonal violence. In most cases ( 65 per cent) the injury was unintentional and in 9 per cent the intent was undetermined.

The number of hospitalisations attributed to firearm injury fell in the 1980s. In 1983, there were 398 admissions due to gunshot wounds in NSW hospitals. The number of admissions subsequently fell to 322 in 1986 and 244 in 1988-9, a 40 per cent reduction on 1983 numbers. A closer examination of the data reveals the decline occurred only for unintentional firearm injuries, which fell from 301 admissions in 1983 to 159 in 1988-9. It is not clear whether this reflects a change in admission policy or a major decline in the number of serious cases.

\section{INTENTIONAL INJURY}

\section{Self-inflicted injury}

Most cases of serious firearm-related injury were selfinflicted. Self-inflicted injuries accounted for 75 per cent of firearm deaths and 15 per cent of the hospital admissions. About 190 people each year make a serious suicide attempt using a firearm and around 80 per cent of these attempts result in death.

In the broader context of suicide, firearm-related suicides accounted for 24 per cent of the 3124 suicides recorded between 1984 and 1988 in NSW. Firearms were the most common agents used in male suicides (29 per cent).

\section{Interpersonal violence}

The use of firearms intentionally to injure other people was responsible for 20 per cent of firearmrelated deaths and 11 per cent of hospital admissions. About 70 people are seriously wounded by firearms as the result of interpersonal violence each year and 


\section{Firearm injuries in NSW}

\section{- Confinued from page 111}

an estimated 60 per cent of these victims die from their injuries. Furthermore, the 204 firearm homicides in 1984-88 represented 37 per cent of the total of 542 homicides recorded during that time.

\section{UNINTENTIONAL INJURY}

In most hospital admissions for firearm-related injuries, the shootings were unintentional in nature (65 per cent) while less than 5 per cent of the deaths were similarly classified. Overall, there were around 200 serious unintentional firearm injuries in NSW during 1988-9. This figure appears to have fallen quite dramatically during the 1980 s. Less than one in twenty of the serious injuries in this category resulted in death.

\section{WHERE TO FROM HERE}

Firearm injuries are a significant problem in NSW; they rank third as a cause of injury death, and cause an estimated 450 serious injuries a year. Of particular concern are the high rates for young people, males and rural residents, and the major role of firearms in intentional injury. An attempted suicide with a firearm has an 80 per cent chance of succeeding. In addition, the number of firearm deaths has remained relatively stable since the late $1960 \mathrm{~s}$, while other major causes of injury death — such as motor vehicle crashes - have declined dramatically.

To generate further information to guide prevention strategies for firearm injuries we will:

- analyse data (including more recent data) relating to the magnitude, characteristics and circumstances of firearm injuries;

口 obtain information about the number, type and distribution of firearms in NSW, including regulations relating to firearm ownership and use; monitor the impact of changes in firearm regulations and other interventions on firearm injuries and deaths; and review the international literature.

Injury Advisory Group, NSW Health Department

David Lyle*, Shing Chung Fung*, Judith E Jones*, Peter Lewis*, Jane Elkington \#, Victor Carey ${ }^{\dagger}$

* Epidemiology and Health Services Evaluation Branch \# Health Promotion Unit

$\uparrow$ Childsafe NSW

\section{FIGURE 1}

MAJOR CAUSES OF INJURY-RELATED DEATHS NSW, 1984-1988

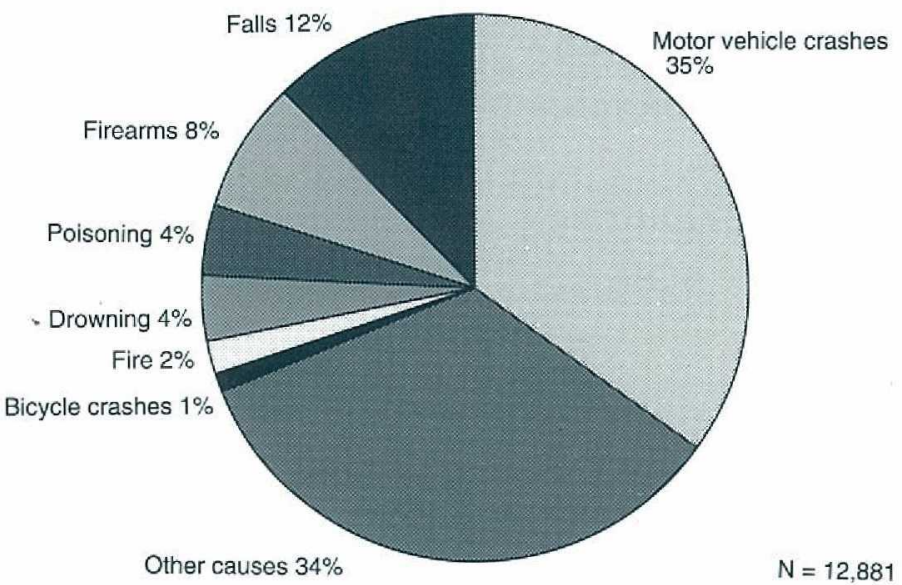

\section{FIGURE 2}

FIREARM-RELATED DEATHS BY AGE AND SEX NSW, 1984-1988

NUMBER OF DEATHS RATE PER 100,000 POPULATION PER YEAR

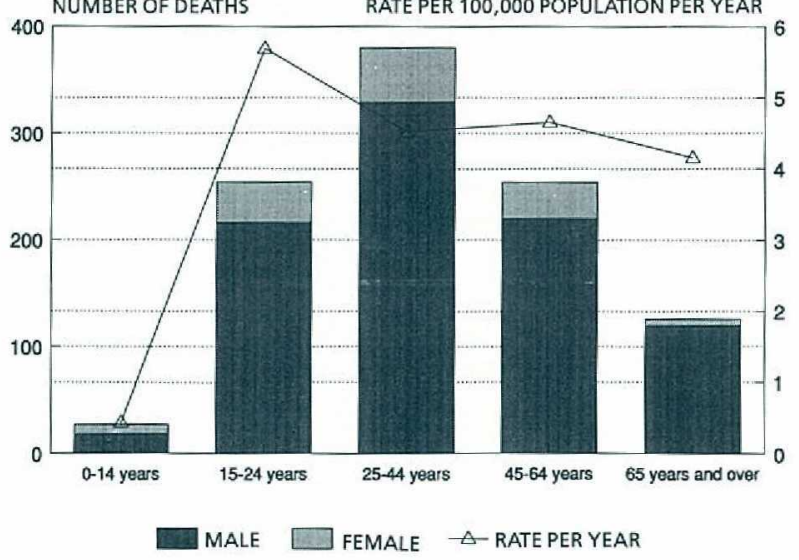

\section{FIGURE 3}

FIREARM-RELATED MORTALITY RATES (THREE-YEAR MOVING AVERAGE) (THREE-YEAR MOV

RATE PER 100,000 POPULATION

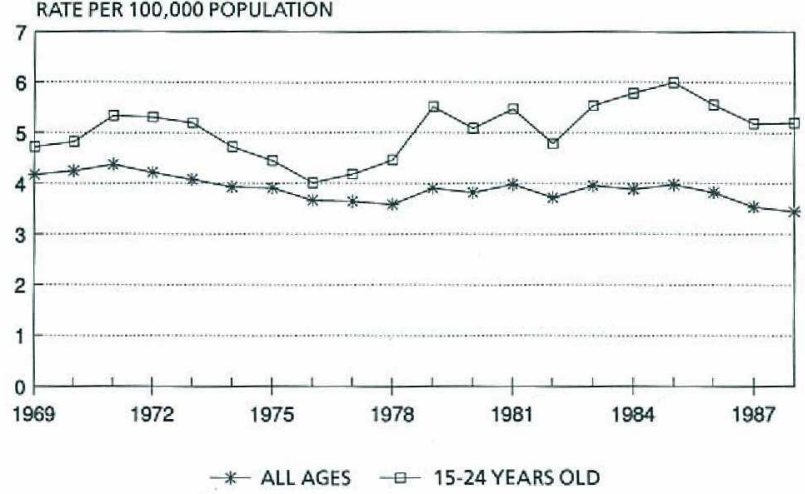

